\title{
Effects of Chronic Fetal Hyperglycemia upon Oxygen Consumption in the Ovine Uterus and Conceptus
}

\author{
Anthony F. Philipps, Patricia J. Porte, Seth Stabinsky, \\ Ted S. Rosenkrantz, and John R. Raye \\ Departments of Pediatrics and Obstetrics and Gynecology, \\ The University of Connecticut Health Center, \\ Farmington, Connecticut 06032
}

bstract. Hyperglycemia has been shown to induce arterial hypoxemia in the chronically catheterized fetal sheep. To investigate the mechanism behind this glucose-induced hypoxemia, eight pregnant ewes and their fetuses were studied. Fetal glucose infusion $(11.9 \pm 0.6 \mathrm{mg}$ glucose $/ \mathrm{kg}$ per min) was associated with a doubling of the fetal plasma glucose concentration with concomitant elevation of the umbilical vein-distal arterial $\mathrm{O}_{2}$ content difference by $24 \mathrm{~h}$ of infusion $(P<0.01)$. Calculated fetal $\mathrm{O}_{2}$ consumption increased from $8.1 \pm 0.4 \mathrm{ml} / \mathrm{kg}$ per min in the control period to a maximum value of $10.6 \pm 0.3$ $\mathrm{ml} / \mathrm{kg}$ per min by third infusion day $(P<0.01)$, which is an increase of $\sim 30 \%$. The degree of stimulation of fetal $\mathrm{O}_{2}$ consumption was related to the degree of fetal hyperglycemia but not to the degree of fetal hyperinsulinemia. The increase in fetal $\mathrm{O}_{2}$ consumption was accompanied by a significant increase in fetal $\mathrm{O}_{2}$ extraction with no change in either fetal $\mathrm{O}_{2}$ delivery or fetal blood $\mathrm{O}_{2}$ affinity. In addition, fetal hypercapnea with a mild fetal respiratory acidosis was induced by fetal hyperglycemia. The increase in fetal arterial $\mathrm{PCO}_{2}$ was linearly related $(P<0.001)$ to the magnitude of increase in fetal $\mathrm{O}_{2}$ consumption. These studies suggest that chronic fetal hyperglycemia induces a state of accelerated fetal oxidative metabolism and may be important in explaining the etiology behind certain unusual findings in human infants of diabetic mothers.

This work was presented in part before the Annual Meeting of the American Pediatric Society and the Society for Pediatric Research, Washington, DC, 3-6 May 1983.

Address reprint requests to Dr. Philipps.

Received for publication 28 October 1983 and in revised form 22 March 1984.

J. Clin. Invest.

(c) The American Society for Clinical Investigation, Inc. 0021-9738/84/07/0279/08 \$1.00

Volume 74, July 1984, 279-286

\section{Introduction}

The classical findings of macrosomia and postnatal hypoglycemia in newborn infants born to women with diabetes mellitus are thought to be due to the excesses in substrate uptake and insulin secretion of the fetus $(1,2)$. However, certain clinical and pathological findings suggest that other disorders seen in these infants, such as polycythemia, hyperbilirubinemia, and late fetal demise $(2,3)$, may be related to occult in utero hypoxemia. Using a chronically catheterized fetal lamb preparation, it has recently been demonstrated that long-term fetal glucose infusion induces a relative fetal arterial hypoxemia (4), and that the degree of this hypoxemia is related to the magnitude of the hyperglycemia. It has been unclear whether or not this glucose-induced hypoxemia is secondary to abnormalities in uterine and/or fetal oxidative metabolism or is simply due to altered placental gas transport. The purpose of the current study was to investigate each of these possible etiologies using the fetal lamb model with chronic defined fetal glucose infusions.

\section{Methods}

Surgical preparation. Eight pregnant ewes were studied between 120 and 140-d gestation (term gestation in the sheep is $\sim 150 \mathrm{~d}$ ). Five had singleton pregnancies. Preoperatively, all ewes were anesthetized with intravenous sodium pentobarbital and intrathecal pontocaine. At hysterotomy, polyvinyl chloride catheters were implanted into the fetal distal aorta (postductal) and inferior vena cava using a pedal approach. Of the three twin gestations, only one fetal twin from each was catheterized. Umbilical venous catheters were inserted directly into the common umbilical vein (5) or into a cotyledonary branch and advanced proximally until the catheter tip was in the common umbilical vein. Maternal catheters were placed in the distal aorta via a femoral insertion and into the common uterine vein of the pregnant uterine horn (5). An amniotic space catheter was inserted for pressure monitoring and instillation of antibiotics. All catheters were then tunnelled subcutaneously to a pouch on the ewe's flank. Catheter tip placement was confirmed at autopsy in the majority of preparations and was adequate in all. A 4-5-d postoperative recovery period was allowed prior to experimentation. Postoperative management was performed as previously described (6). All animals were housed in individual carts for the duration of the experimental protocol and allowed food and water ad libitum.

Experimental protocol. During a control period of $2 \mathrm{~d}$, fetal and maternal arterial blood samples were obtained for plasma concentrations 
of glucose and insulin as well as arterial blood gases $\left(\mathrm{pH}, \mathrm{PCO}_{2}\right.$ and $\mathrm{PO}_{2}$ ), hematocrit, and serum solids. Twice daily, samples were drawn simultaneously from the uterine vein and maternal aorta, and the umbilical vein and fetal distal aorta to assess venoarterial blood concentration differences of oxygen $\left(\mathrm{O}_{2}\right)$ across the uterine and umbilical circulations. Uterine and umbilical blood flows were also measured twice daily using the antipyrine steady state diffusion technique (7). Uterine and fetal $\mathrm{O}_{2}$ consumptions $\left(\mathrm{Q}_{2}\right)^{1}$ were calculated from the Fick Principle as the product of the respective blood flow and arteriovenous $\mathrm{O}_{2}$ content difference measurements. Uteroplacental $\mathrm{O}_{2}$ consumption was derived as the difference between uterine and fetal $\mathrm{Q}_{2}$ 's. Fetal $\mathrm{O}_{2}$ delivery was calculated as the product of umbilical blood flow and umbilical venous $\mathrm{O}_{2}$ content. Fetal $\mathrm{O}_{2}$ extraction was calculated as the ratio between fetal $\mathrm{O}_{2}$ consumption and fetal $\mathrm{O}_{2}$ delivery.

At the end of the 2-d control period, fetal glucose infusion was begun at a rate of $12.5 \mathrm{mg}$ glucose/ $\mathrm{kg}$ estimated fetal weight per min and continued for $72 \mathrm{~h}$. A solution of $50 \%$ glucose in sterile water was infused into the fetal vena caval catheter using precalibrated syringe pumps (Orion Research Products, Cambridge, MA; Harvard Apparatus Co., South Natick, MA). These infusions resulted in infusate delivery rates between 3 and $6 \mathrm{ml} / \mathrm{h}$. At daily intervals beginning $24 \mathrm{~h}$ after the commencement of fetal glucose infusion, venoarterial sampling across the uterine and umbilical circulations was performed twice for estimation of blood flow, blood $\mathrm{O}_{2}$ content, and calculation of $\mathrm{O}_{2}$ consumption. Since the determination of the rate of fetal weight gain with advancing gestational age was impossible during the experiments, the estimates of fetal oxygen consumption were calculated arbitrarily using the estimated preinfusion weight for control and experimental values alike. Fetal weight increases by $\sim 2-4 \% / \mathrm{d}$ in late gestation ( 8 ) and some, but not proportionate, increases in fetal oxygen consumption (expressed as $\mathrm{ml} / \mathrm{min}$ ) also occur after 120-130-d gestation $(9,10)$. However, when expressed on a per weight basis, fetal oxygen consumption falls during this period. Thus, the assignation of control fetal weight to the above calculations should not obscure significant changes in fetal oxygen consumption. Four fetuses of similar gestational age were used as controls to adjust for the possible increases in oxygen consumption due to advancing gestational age. Samples were obtained $5 \mathrm{~d}$ apart from appropriate fetal vascular catheters and analyzed for blood flow, $\mathrm{O}_{2}$ content, and calculations of fetal $\mathrm{O}_{2}$ consumption. In addition, samples of daily maternal and fetal arterial blood were obtained for measurement of plasma glucose and insulin concentrations, blood gases, hematocrit, and serum solids. In selected experiments, fetal arterial blood at $50 \%$ saturation $\left(\mathrm{P}_{50}\right)$ and erythrocyte 2,3-diphosphoglycerate (2,3-DPG) concentration were assessed serially to note any possible alterations in fetal hemoglobin- $\mathrm{O}_{2}$ affinity.

During control and experimental periods, fetal heart rate and arteriovenous blood pressure differences across the uterine and umbilical circulations were measured using Statham P23-Ia pressure transducers (Statham Laboratories, Hato Rey, PR) and a Hewlett Packard HP7796A Physiologic Recorder (Hewlett-Packard Co., Waltham, MA). Pressure transducers were calibrated against a standard mercury manometer. Fetal arterial and umbilical venous pressures were measured using the intraamniotic fluid pressure as a zero reference. Uterine and umbilical vascular resistances were calculated as the ratio between the appropriate arteriovenous pressure difference and the respective blood flow.

1. Abbreviations used in this paper: 2,3-DPG, 2,3-diphosphoglycerate; IDM, infants of diabetic mothers; $\mathrm{P}_{\mathbf{5 0}}$, arterial blood at $50 \%$ saturation; $\mathrm{Q}_{2}$, fetal $\mathrm{O}_{2}$ consumption.
Biochemical methods. Plasma glucose concentrations were measured using a glucose oxidase technique (Beckman Instruments, Inc., Palo Alto, CA). Whole blood $\mathrm{O}_{2}$ content was measured using a Lex- $\mathrm{O}_{2}-$ Con (Lexington Instruments, Waltham, MA) calibrated daily against distilled water saturated with $\mathrm{O}_{2}$ at $\mathrm{O}^{\circ} \mathrm{C}$. Blood for $\mathrm{O}_{2}$ content determinations were withdrawn into capillary tubes pretreated with $\mathrm{NaF}$. Plasma antipyrine concentrations were determined using the Technicon Autoanalyzer (Technicon Instruments Corp., Tarrytown, NY). Arterial blood gases were measured using a Corning \#178 Blood Gas Analyzer (Corning Medical Products, Medfield, MA). $\mathbf{P}_{50}$ measurements were performed at $37^{\circ} \mathrm{C}$ and utilized a tonometric method (IL237 tonometer; Instrumentation Laboratory, Inc., Lexington, MA). Fetal erythrocyte 2,3-DPG concentrations were measured using the enzymatic method of Keitt (11). Plasma insulin concentrations were determined using a modified insulin radioimmunoassay (6) with ovine insulin standards (kindly supplied by Dr. M. A. Root, Eli Lilly Laboratories, Indianapolis, IN).

Statistical methods. All results are expressed as mean \pm 1 SEM. Statistical significance was assessed using the paired Student's $t$ test and two-way analyses of variance. Linear regression analyses were performed using the least squares method.

\section{Results}

Nine separate glucose infusions were performed in the fetal lambs. Glucose infusion rates were $11.9 \pm 0.6 \mathrm{mg}$ glucose $/ \mathrm{kg}$ per min when corrected for known fetal delivery weights. As shown in Fig. 1, fetal glucose infusion resulted in a sustained increase in fetal plasma arterial glucose concentration from $26.0 \pm 1.9$ to $58.8 \pm 3.7 \mathrm{mg} / \mathrm{dl}$ during the $72-\mathrm{h}$ infusion period $(P<0.001)$. Umbilical venous $\mathrm{O}_{2}$ content fell slightly from $10.7 \pm 0.6$ to $9.2 \pm 0.9 \mathrm{mg} / \mathrm{dl}$, but the change was not statistically significant. In contrast, fetal distal aortic $\mathrm{O}_{2}$ content fell from the basal value of $7.3 \pm 0.5$ to $5.7 \pm 0.4 \mathrm{ml} / \mathrm{dl}$ by $24 \mathrm{~h}$ of infusion $(P<0.01)$ and reached a nadir of $4.9 \pm 0.7 \mathrm{ml} / \mathrm{dl}(2.2 \pm 0.4 \mathrm{ml} / \mathrm{dl}$ below base line) by the third day of glucose infusion $(P<0.01)$. Consequently, fetal hyperglycemia induced a rise in the umbilical venoarterial $\mathrm{O}_{2}$ content difference by $24 \mathrm{~h}$ of infusion (from $3.5 \pm 0.2$ to $4.3 \pm 0.2 \mathrm{ml} / \mathrm{dl}, P<0.01$ ). The elevation in umbilical (venoarterial) $\mathrm{O}_{2}$ content was maintained throughout the experimental period (Fig. 1).

Glucose infusion produced no alteration in umbilical blood flow from the basal value of $232 \pm 7 \mathrm{ml} / \mathrm{kg}$ per min $(828 \pm 25$ $\mathrm{ml} / \mathrm{min}$ ). Control fetal $\mathrm{QO}_{2}$ as calculated from the Fick equation was $8.1 \pm 0.4 \mathrm{ml} / \mathrm{kg}$ per min. During fetal hyperglycemia, fetal $\mathrm{Q}_{\mathrm{O}_{2}}$ rose to $9.4 \pm 0.3 \mathrm{ml} / \mathrm{kg}$ per min by day 1 of infusion and to a maximum value of $10.6 \pm 0.3 \mathrm{ml} / \mathrm{kg}$ per min by day 3 $\left(\Delta \mathrm{Q}_{\mathrm{O}_{2}}=+2.6 \pm 1.6 \mathrm{ml} / \mathrm{kg}\right.$ per min, $\left.P<0.01\right)$. When pooled individual values for the fetal $\mathrm{Q}_{\mathrm{O}_{2}}$ were compared with their paired plasma arterial glucose concentrations (Fig. 2), a significant $(P<0.001)$ relationship was apparent between the degree of fetal glycemia and stimulation of fetal oxygen consumption.

The calculations of fetal $\mathrm{O}_{2}$ delivery and extraction during fetal hyperglycemia in the experimental animals are presented in Table I. Although a fall in fetal $\mathrm{O}_{2}$ delivery was noted at 24 $\mathrm{h}$ of glucose infusion, this change amounted to $\mathrm{a}<7 \%$ fall from base line and was statistically insignificant. In contrast, fetal $\mathrm{O}_{2}$ 


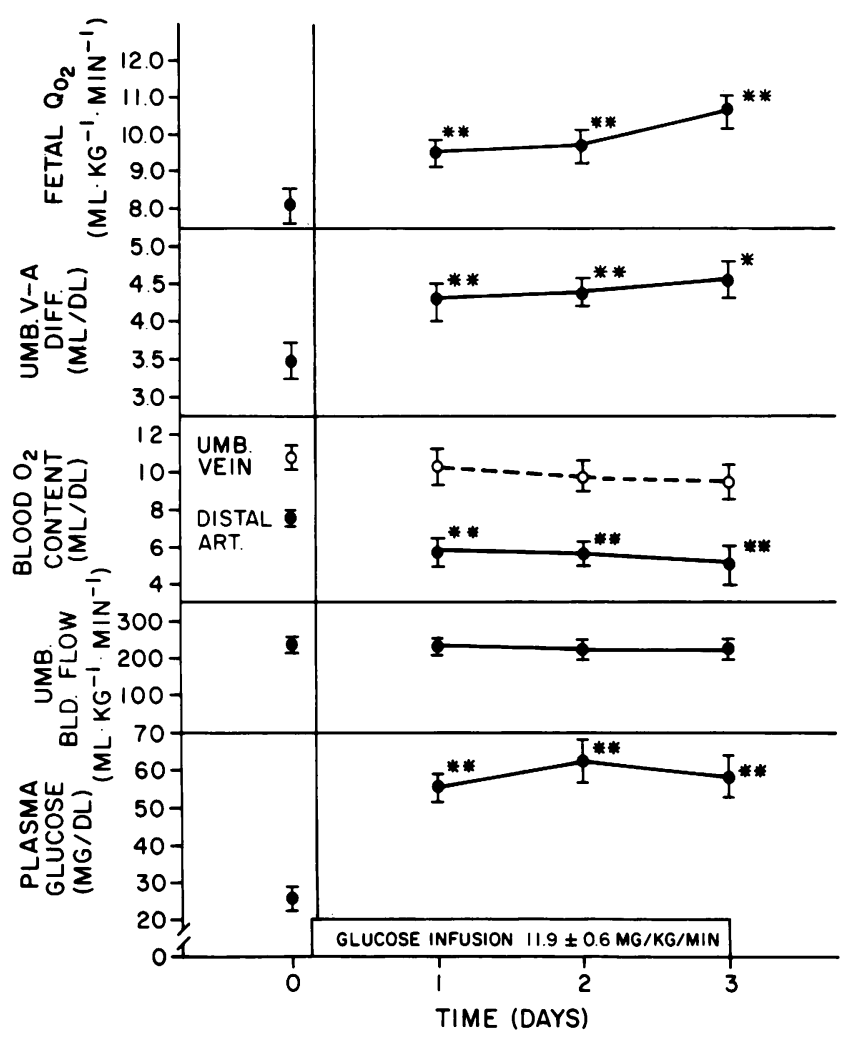

Figure 1. Fetal plasma glucose concentrations, umbilical blood flow (umb. bld. flow), and fetal $\mathrm{O}_{2}$ contents and consumptions $\left(\mathrm{Q}_{2}\right)$ before and during nine glucose infusions in eight fetal lambs. $*, P<$ $0.05 ; * *, P<0.01$.

extraction increased successively above the basal value of $33.8 \pm 2.5 \%$ to a maximum of $51.4 \pm 4.5 \%(P<0.01)$ by day 3 of infusion.

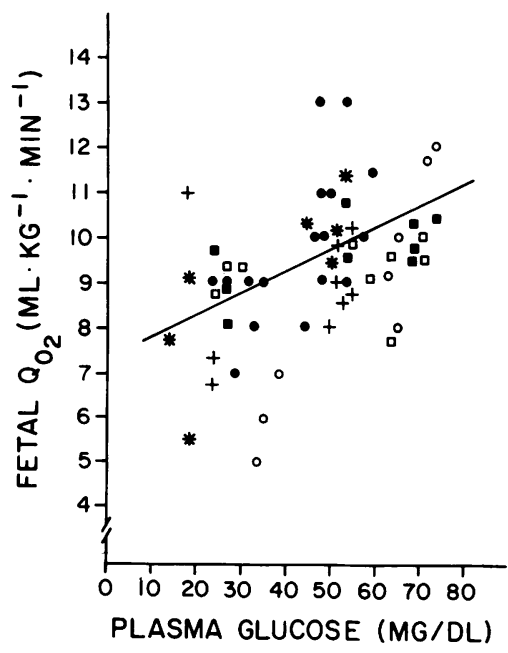

Figure 2. Relationship between fetal plasma glucose concentrations and $\mathrm{Q}_{2}$ during control and experimental periods. Each symbol represents a different animal preparation. $(n=59, r$ $=0.46, \mathrm{y}=0.05 \mathrm{x}$ $+7.17, P<0.001)$.
Table I. Comparison between Fetal Oxygen Delivery and Oxygen Extraction before and during Fetal Glucose Infusion

\begin{tabular}{lllll}
\hline & Control & Day 1 & Day 2 & Day 3 \\
\hline $\begin{array}{l}\text { Fetal } \mathrm{O}_{2} \text { delivery } \\
(\mathrm{ml} / \mathrm{kg} \text { per min })\end{array}$ & $24.8 \pm 1.6$ & $22.6 \pm 1.7$ & $21.4 \pm 1.7$ & $21.7 \pm 1.8$ \\
$\begin{array}{l}\text { Fetal } \mathrm{O}_{2} \text { extraction } \\
(\%)\end{array}$ & $33.8 \pm 2.5$ & $42.7 \pm 3.0^{* *}$ & $46.4 \pm 2.6^{* *}$ & $51.4 \pm 4.5^{* *}$
\end{tabular}

** $P<0.01$, difference from control.

In contrast, fetal oxygen consumption in the four control fetuses increased from $23.8 \pm 2.2$ to $24.4 \pm 2.8 \mathrm{ml} / \mathrm{min}(8.5 \pm 0.8$ to $8.7 \pm 0.9 \mathrm{ml} / \mathrm{kg}$ per $\mathrm{min}$ ) over a $5-\mathrm{d}$ period similar to that between initiation and completion of each infusion experiment. This elevation amounted to a $3 \%$ increase in $\mathrm{Q}_{2}$ due to advancing gestational age.

In seven of the glucose infusion experiments, simultaneous sampling from the uterine as well as the umbilical circulation was performed through the majority of the experimental period. Although a trend was evident, no changes in uterine venous or arterial $\mathrm{O}_{2}$ content nor in uterine blood flow were noted from base line. As shown in Fig. 3, although the calculated uterine $\mathrm{Q}_{2}$ rose from $50.4 \pm 4.9 \mathrm{ml} / \mathrm{min}$ to a maximum value of $57.8 \pm 7.5$ $\mathrm{ml} / \mathrm{min}$ by day 3 of infusion, this change was not statistically significant. Umbilical $\mathrm{Q}_{2}$ (not corrected for fetal weight) rose

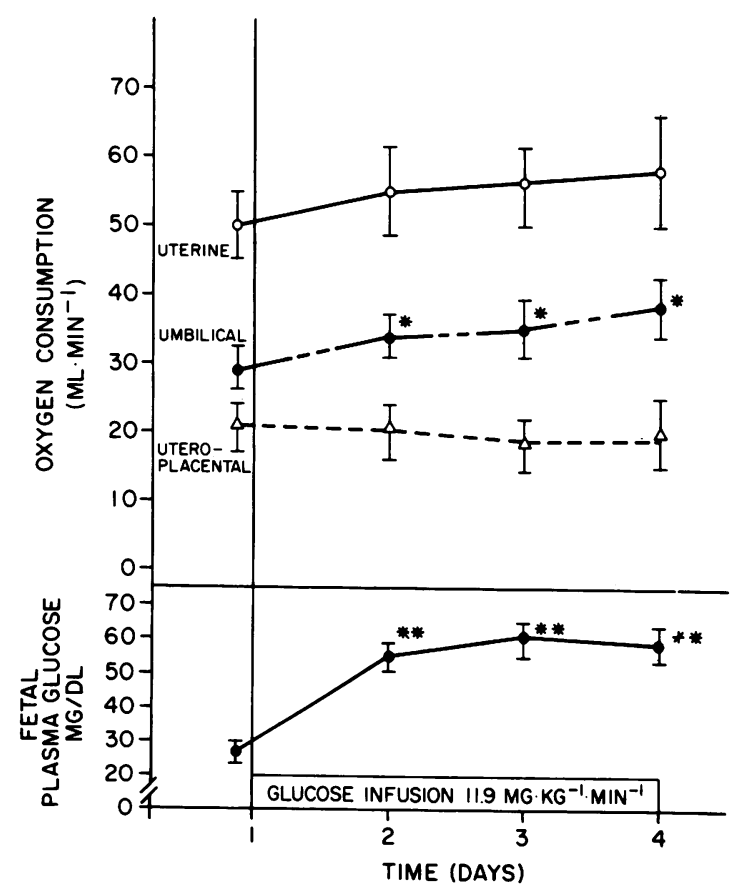

Figure 3. Changes in fetal plasma glucose concentration and $\mathrm{O}_{2}$ consumption of uterus, fetus (umbilical), and utero placental mass occurring during fetal glucose infusion. $\left({ }^{*} P<0.05\right)$. 
Table II. Vascular Parameters in Uterine and Umbilical Circulations before and during Fetal Hyperglycemia

\begin{tabular}{|c|c|c|c|c|c|c|c|}
\hline & \multicolumn{2}{|c|}{ Blood flow (F) $(\mathrm{ml} / \mathrm{kg} / \mathrm{min})$} & \multirow{2}{*}{$\begin{array}{l}\text { Fetal heart } \\
\text { rate }\end{array}$} & \multicolumn{2}{|c|}{$\begin{array}{l}\text { A-V Pressure }(\mathbf{P}) \text { difference } \\
\text { (torr) }\end{array}$} & \multicolumn{2}{|c|}{$\begin{array}{l}\text { Vascular resistance (R) } \\
(\text { torr } / \mathrm{ml} / \mathrm{kg} / \mathrm{min})\end{array}$} \\
\hline & $\mathrm{F}_{\mathrm{ut}}$ & $F_{u m b}$ & & $\mathrm{P}_{\mathrm{ut}}$ & $P_{u m b}$ & $\mathbf{R}_{\mathrm{ut}}$ & $\mathbf{R}_{\mathrm{umb}}$ \\
\hline & & & beats/min & & & & \\
\hline Control & $395 \pm 36(7)^{*}$ & $228 \pm 9(8)$ & $186 \pm 7(8)$ & $69 \pm 3(8)$ & $30 \pm 3(8)$ & $0.19 \pm 0.03(8)$ & $0.14 \pm 0.02(8)$ \\
\hline Day 1 & $394 \pm 34(7)$ & $219 \pm 11(8)$ & $203 \pm 11(8)$ & $70 \pm 5(7)$ & $29 \pm 2(8)$ & $0.19 \pm 0.03(7)$ & $0.13 \pm 0.02(7)$ \\
\hline Day 2 & $396 \pm 37(7)$ & $223 \pm 13(8)$ & $197 \pm 10(8)$ & $67 \pm 4(7)$ & $31 \pm 3(7)$ & $0.18 \pm 0.03(7)$ & $0.14 \pm 0.02(6)$ \\
\hline Day 3 & $416 \pm 67(5)$ & $241 \pm 15(7)$ & $197 \pm 12(7)$ & $71 \pm 4(5)$ & $32 \pm 3(5)$ & $0.20 \pm 0.05(5)$ & $0.13 \pm 0.01(6)$ \\
\hline
\end{tabular}

ut, uterine; umb, umbilical. *, ( ), number of observations.

to a similar degree as the uterine $\mathrm{QO}_{2}$ (from $29.4 \pm 3$ to $38.5 \pm 4.1$ $\mathrm{ml} / \mathrm{min}$ by day 3 of glucose infusion, $P<0.05$ ), and thus, no change in the calculated uteroplacental $\mathrm{Q}_{\mathrm{O}_{2}}$ was noted from the basal value of $21.6 \pm 2.6 \mathrm{ml} / \mathrm{min}$.

Fetal hyperglycemia induced no alterations in fetal heart rate nor in fetal or maternal blood pressures (Table II). In addition, no changes were seen in uterine or umbilical vascular resistancès. No changes in fetal hematocrit nor in total serum solids were detected (Table III). The $50 \%$ hemoglobin- $\mathrm{O}_{2}$ saturation point $\left(\mathbf{P}_{50}\right)$ of fetal distal arterial blood was determined during five of the infusions (Table III). Hyperglycemia did not change the basal $P_{50}$ of $15.8 \pm 0.6$ torr. In four experiments, fetal

Table III. Comparison of Changes in Fetal Arterial Blood Gases and Hemoglobin-oxygen Affinity before and during Fetal Glucose Infusion

\begin{tabular}{|c|c|c|c|c|}
\hline & \multicolumn{4}{|c|}{$\begin{array}{l}\text { Fetal Arterial Blood Values } \\
\text { Day }\end{array}$} \\
\hline & 0 & 1 & 2 & 3 \\
\hline \multicolumn{5}{|l|}{ Hematocrit } \\
\hline (\%) & $33.9 \pm 0.9(9)$ & $30.4 \pm 3.7(9)$ & $32.8 \pm 1.3(9)$ & $31.0 \pm 1.3(9)$ \\
\hline $\mathrm{pH}$ & $7.39 \pm 0.01$ & $7.36 \pm 0.01^{*}$ & $7.40 \pm 0.01$ & $7.39 \pm 0.01$ \\
\hline $\mathrm{PCO}_{2}$ (torr) & $44.2 \pm 2.1$ & $48.0 \pm 1.6^{*}$ & $48.6 \pm 1.7 \ddagger$ & $46.9 \pm 1.7$ \\
\hline $\mathrm{PO}_{2}$ (torr) & $17.1 \pm 0.9$ & $15.7 \pm 1.1$ & $14.2 \pm 0.5 \ddagger$ & $15.1 \pm 1.0^{*}$ \\
\hline $\begin{array}{l}\text { Base excess } \\
\text { (meq/liter) }\end{array}$ & $+1.6 \pm 0.9$ & $+1.3 \pm 1.4$ & $+4.3 \pm 1.0 \ddagger$ & $+3.0 \pm 1.0$ \\
\hline $\begin{array}{l}\text { Total serum } \\
\text { solids }(g / d l)\end{array}$ & $\begin{array}{l}4.1 \pm 0.1 \\
\text { Control }\end{array}$ & $4.2 \pm 0.1$ & $\begin{array}{l}\quad 4.2 \pm 0.1 \\
\text { Day } 3\end{array}$ & $4.4 \pm 0.1$ \\
\hline $\begin{array}{l}\text { Arterial } \mathrm{P}_{50} \\
\quad \text { (torr) } \\
2,3-\mathrm{DPG} \\
\quad \text { (mol/ml } \\
\text { erythrocyte) }\end{array}$ & $15.8 \pm 0.6(5)$ & & $1.32 \pm 0.24$ & \\
\hline
\end{tabular}

Difference from control: ${ }^{*}, P<0.05 ; \ddagger, P<0.01$. erythrocyte 2,3-DPG concentrations were determined as well and were unaltered by chronic hyperglycemia.

Fetal arterial blood gases assessed daily showed significant changes during hyperglycemia (Table III). As expected, arterial $\mathrm{PO}_{2}$ fell significantly $(P<0.01)$ by $48 \mathrm{~h}$ of glucose infusion. Arterial $\mathrm{PCO}_{2}$ rose significantly by $24 \mathrm{~h}$ of glucose infusion and remained elevated throughout the experimental period, although this elevation was significant on days 1 and 2 only. This hypercapnea was accompanied by a significant fall in $\mathrm{pH}$ on day 1 with a subsequent increase in calculated buffer base noted on day 2. The sum total of events indicated an early respiratory acidosis induced by hyperglycemia, with later metabolic compensation and an ongoing arterial hypoxemia. No changes in maternal $\mathrm{pH}$ or $\mathrm{PO}_{2}$ were noted during the experimental period from control. Maternal arterial $\mathrm{PCO}_{2}$ during the control period was $32.6 \pm 1.5$ torr and did not change significantly during days 1 and 2 of fetal glucose infusion. A small but statistically significant decrease in $\mathrm{PCO}_{2}$ to $30.3 \pm 1.2$ torr $(P<0.02)$ was noted on day 3 of infusion. When the fetal $\mathrm{PCO}_{2}$ data were related to changes in fetal $\mathrm{Q}_{2}$, no relationship was apparent because of interanimal variability in both parameters. However, when fetal $\mathrm{Q}_{2}$ 's were expressed as percent from control and fetal $\mathrm{PCO}_{2}$ 's expressed as fetomaternal ratios to decrease this variability, a relationship is apparent (Fig. 4). One unusual animal (open circles) responded to hyperglycemia with a large increase in $\mathrm{Q}_{2}$ but little change in fetal arterial $\mathbf{P C O}_{2}$. It is unclear whether or not the observed changes in this animal represented experimental error or a true lack of response. Without the addition of this animal to the data, a highly significant relationship $(P<0.001)$ is apparent between fetal $\mathrm{Q}_{2}$ and fetal $\mathrm{PCO}_{2}$.

Fetal hyperglycemia induced significant elevations in fetal plasma arterial insulin concentration from a control value of $12.5 \pm 1.8 \mu \mathrm{U} / \mathrm{ml}$ to a peak concentration of $28.9 \pm 8.3 \mu \mathrm{U} / \mathrm{ml}$ by day 2 of infusion $(P<0.01)$. Overall insulin response, however, was quite variable between animals. One fetus $(+)$ appeared not to respond to glucose infusion with any rise in insulin concentration. Use of weighted means or averaging data from each animal neither altered the regression equation nor the correlation 


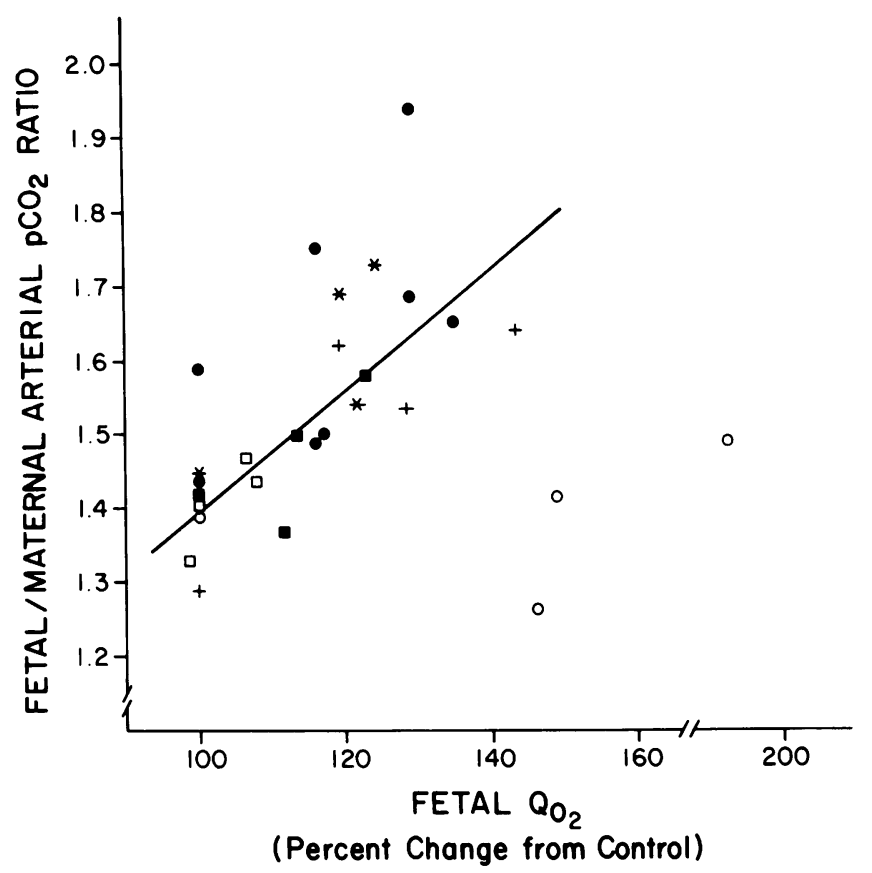

Figure 4. Relationship between $\mathrm{Q}_{\mathrm{O}_{2}}$ expressed as percent of control and fetal/maternal arterial $\mathrm{PCO}_{2}$ ratios. One animal $(0)$ has been deleted from regression calculations. $(n=24, \mathrm{y}=0.01 \mathrm{x}+0.6, r$ $=0.69, P<0.001$ ).

coefficient. Although a significant relationship $(P<0.001)$ was noted between the rise in fetal plasma glucose and the simultaneously sampled plasma insulin concentration (Fig. 5), no relationship was noted between fetal insulin concentrations and fetal $\mathrm{Q}_{2}$ before and during hyperglycemia. No changes in maternal glucose concentrations were observed during the experimental period.

\section{Discussion}

Previous work using the chronically catheterized fetal lamb model has demonstrated that chronic fetal hyperglycemia is associated with significant distal arterial hypoxemia and a mild arterial hypercapnea (4). With pronounced hyperglycemia, progressive hypoxia, metabolic acidosis, and fetal demise were evident. Although a linear relationship was apparent between the degree of hyperglycemia and the relative fall in fetal arterial $\mathrm{O}_{2}$ content, the mechanism behind the fetal hypoxemia was unclear. Major hypotheses to explain these alterations included either stimulation of fetal and/or uteroplacental $\mathrm{O}_{2}$ consumption or depression of transplacental $\mathrm{O}_{2}$ transport due either to decreased $\mathrm{O}_{2}$ diffusion or altered fetal hemoglobin- $\mathrm{O}_{2}$ affinity.

The present data may be interpreted to indicate that the development of hyperglycemia in the fetal lamb induces an acceleration of the fetal metabolic rate and that the increase in

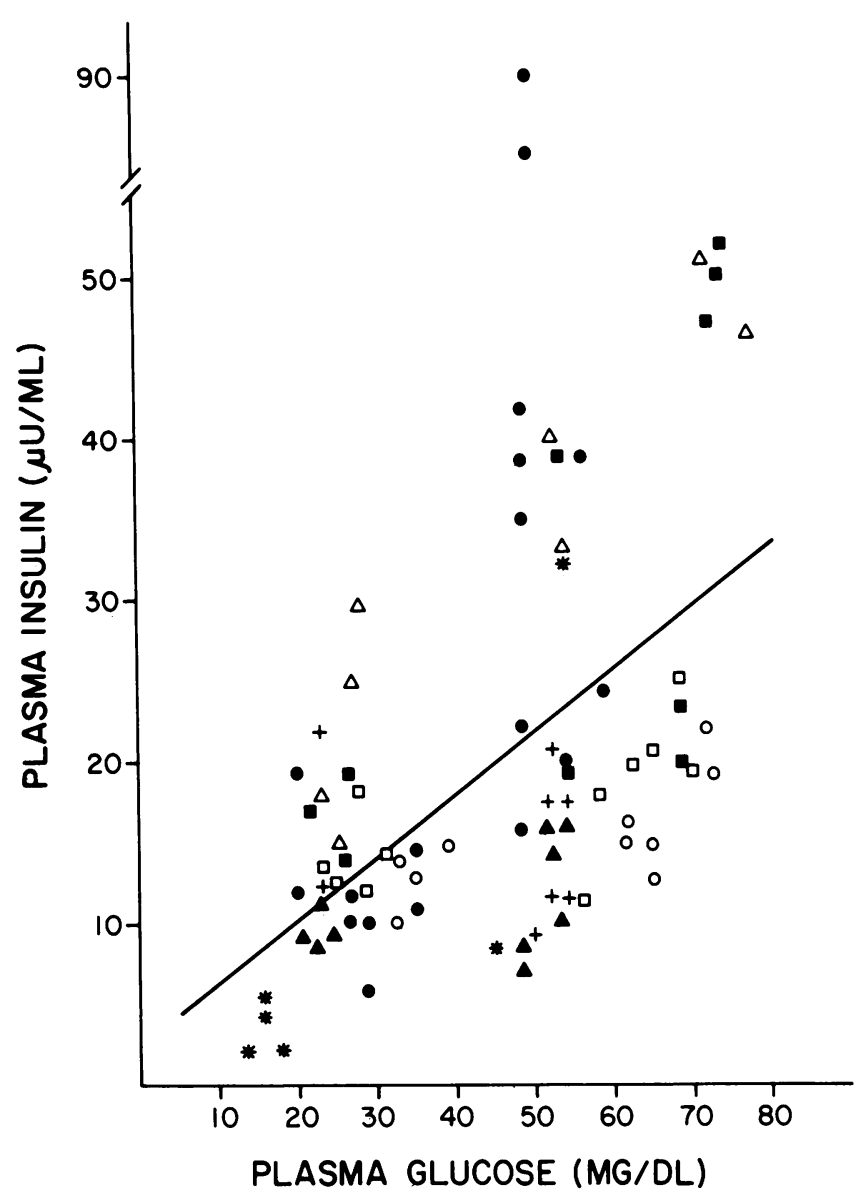

Figure 5. Relationship between fetal plasma glucose and insulin concentrations during control and experimental periods. Each symbol represents a different animal preparation. $(n=83, r=0.43, y=0.39$ $\mathrm{x}+2.24, P<0.001)$.

fetal $\mathrm{O}_{2}$ consumption is almost wholly responsible for the observed fall in preplacental arterial $\mathrm{O}_{2}$ content. Although hyperglycemia has been shown to alter hemoglobin- $\mathrm{O}_{2}$ affinity in diabetic states (12), no changes in fetal hemoglobin- $\mathrm{O}_{2}$ affinity or fetal erythrocyte 2,3-DPG concentrations were observed. In addition, no changes in monitored vascular parameters were noted to account for the above mentioned changes in fetal $\mathrm{O}_{2}$ content.

In further studies using this model (13), concomitant increases in glucose and lactate uptake have been demonstrated during fetal hyperglycemia. It is of particular interest that significant increases in fetal glucose entry rate as well as fetal $\mathrm{O}_{2}$ consumption occurred. Such accelerated oxidative metabolism would be expected to be accompanied by increased fetal $\mathrm{CO}_{2}$ excretion. The small but significant elevation in preplacental arterial $\mathrm{PCO}_{2}$ is suggestive evidence for accelerated $\mathrm{CO}_{2}$ excretion since it is unlikely that transplacental $\mathrm{CO}_{2}$ diffusion would be 
significantly altered in the face of normal $\mathrm{O}_{2}$ diffusion and stable umbilical and uterine blood flows $(14,15)$. From the theoretical model of transplacental $\mathrm{CO}_{2}$ diffusion derived by Hill et al. (15), the observed rise of 3.8 to 4.4 torr in fetal arterial $\mathrm{PCO}_{2}$ would be associated with a $20-30 \%$ increase in fetomaternal $\mathrm{CO}_{2}$ transfer. The observed change in fetal arterial $\mathrm{PCO}_{2}$ could not be accounted for by changes in maternal $\mathrm{CO}_{2}$ tension, which were stable to decreased during the experimental period.

Some precedent exists to suggest that the fetal metabolic rate may be altered under experimental conditions. Lorijn and Longo $(16,17)$ have demonstrated significant stimulation of $\mathrm{O}_{2}$ consumption in fetal lambs using direct fetal infusions of norepinephrine or triiodothyronine. In addition, other recent work $(18,19)$ suggests that acceleration of fetal oxidative metabolism may also occur during fetal insulin infusion. The increase was effected by widening of the umbilical venoarterial $\mathrm{O}_{2}$ content difference without change in umbilical blood flow although significant increases in cardiac output occurred. In the insulin infusion studies, pharmacologic doses of insulin were used and fetal insulin concentrations were generally 2-20-fold above the range seen with the endogenous hyperinsulinemia observed in the present series of experiments. Since in the fetal state, alterations in cardiac output relate more to change in heart rate than stroke volume (20), the absence of significant fetal tachycardia in the chronically hyperglycemic fetal lamb suggests that little increases in cardiac output of the type seen with exogenous insulin infusion occurred. This finding, in addition to the lack of a significant relationship between fetal plasma insulin concentration and either the degree of arterial hypoxemia (4) or the rise in fetal $\mathrm{O}_{2}$ consumption would suggest that the glucoseinduced stimulation of fetal $\mathrm{O}_{2}$ consumption may not be mediated by insulin. However, since the degree of fetal hyperinsulinemia produced was variable, a significant relationship between endogenous hyperinsulinemia and acceleration of fetal $\mathrm{O}_{2}$ consumption may have been obscured.

Stimulation of fetal $\mathrm{O}_{2}$ extraction as seen in the current work has been demonstrated in a variety of other studies dealing with nonhormonal alterations in fetal oxygenation, particularly as a response to states of altered $\mathrm{O}_{2}$ availability. Increases in umbilical $\mathrm{O}_{2}$ extraction have been observed as responses to umbilical vascular ischemia (21), fetal hemorrhage (22), maternal $\mathrm{O}_{2}$ deprivation (23), or decreases in uterine blood flow (24) without concomitant alterations in umbilical blood flows unless hypoxemia was severe. Since neither blood flow nor maternal oxygenation were altered during fetal hyperglycemia, the exact stimulus for the increase in fetal oxygen extraction remains obscure.

At present, little information is available regarding the ability of excesses in substrate delivery to directly alter fetal $\mathrm{O}_{2}$ consumption. However, significant information does exist in in vivo experiments done in adults to indicate that the observed fetal response is not unusual. In the adult human, starvation and refeeding are associated with a fall and subsequent rise in $\mathrm{O}_{2}$ consumption (25). In addition, ingestion of a carbohydrate meal in fasting adults resulted in increases in both $\mathrm{O}_{2}$ consumption and $\mathrm{CO}_{2}$ excretion (26). Several other studies in adult humans supported with parenteral nutrition have tended to confirm the observation that substrate excess induces acceleration of metabolic rate. In studies utilizing parenteral infusions of glucose and amino acids with or without supplemental fat, significant enhancement of alveolar ventilation, $\mathrm{O}_{2}$ consumption, and $\mathrm{CO}_{2}$ excretion were noted when compared with control (27-29). In one case, these resultant increases were so great that they were detrimental to the patient under study (30).

No data are available at present to indicate the metabolic goal of increased fetal metabolism found in the present study. Using data derived by Battaglia et al. (31), the observed increase in fetal lamb $\mathrm{O}_{2}$ consumption would amount to an increase of $\sim 15 \mathrm{kcal} / \mathrm{kg}$ per $\mathrm{d}$ in caloric production. Even a doubling of the short-term fetal growth rate would not be expected to increase caloric expenditure beyond $\sim 5 \mathrm{kcal} / \mathrm{kg}$ per $\mathrm{d}$. In this regard, it is of interest to note that Rurak et al. (32) recently observed that normal fetal respiratory movements can account for up to $17 \%$ of the fetal $\mathrm{O}_{2}$ consumption rate. Several authors $(33,34)$ have documented stimulation of fetal breathing by hyperglycemia in fetal lambs and humans, and thus, giving rise to the possibility that stimulation of muscular work may be in part responsible for the observed increases in fetal $\mathrm{QO}_{2}$. Alternatively, it has been hypothesized (33) that these increases in fetal breathing movements are due to accelerated glucose-induced fetal $\mathrm{CO}_{2}$ production with consequent respiratory center stimulation. Other possible mechanisms for a glucose-induced increase in fetal oxidative metabolism include excessive heat production (35), acceleration of fetal growth, and stimulation of futile cycling within some fetal tissues (36).

No direct information is available from human fetuses or infants of diabetic mothers (IDM's) to support the hypothesis that fetal hyperglycemia induces changes similar to those seen in fetal lambs. MacKay (37) noted a marked umbilical arterial hypoxemia in a small number of IDM's at delivery in the only study available in which $\mathrm{O}_{2}$ content was measured in umbilical vessels. Naeye (38) noted that postmortem hepatic specimens of IDM's contained increases in extramedullary hematopoietic elements and suggested that this finding might be explained on the basis of an erythropoietic response to chronic fetal hypoxemia. Excesses in cord blood erythropoietin have been found in a number of IDM's (39). Since several investigators have demonstrated stimulation of fetal erythropoietin secretion induced by fetal hypoxemia $(40,41)$, particularly during fetal hyperglycemia, it is tempting to speculate that a number of clinical features found in human IDM's (late fetal demise, neonatal polycythemia, and neonatal hyperbilirubinemia) may be the result of hyperglycemia-induced increases in fetal $\mathrm{Q}_{2}$ and relative fetal arterial hypoxemia.

In summary, chronic glucose infusion in the fetal lamb induced a significant increase in fetal $\mathrm{O}_{2}$ consumption within 24 $h$ of the onset of hyperglycemia. The increase in $\mathrm{O}_{2}$ consumption was linearly related to the degree of elevation in fetal plasma 
glucose concentration. The increase in $\mathrm{O}_{2}$ consumption was due to increased fetal $\mathrm{O}_{2}$ extraction and not due to alterations in fetal blood $\mathrm{O}_{2}$ affinity or in placental $\mathrm{O}_{2}$ transport. No fetus became hypoxic as judged by the absence of significant metabolic acidosis. However, significant hypercapnea and respiratory acidosis were noted. The findings suggest that defined fetal glucose infusions induced stimulation of fetal oxidative metabolism but had little effect upon placental $\mathrm{O}_{2}$ consumption.

\section{Acknowledgments}

The authors acknowledge the excellent secretarial assistance of Mary Ann Peifer and Lorraine Fox, as well as the technical assistance of W. Davis, R.T., and staff.

This work was supported by grants from the National Institutes of Health (AM26067) and The University of Connecticut Research Foundation.

\section{References}

1. Pedersen, J., B. Bojsen-Moller, and H. Poulsen. 1954. Blood sugar in newborn infants of diabetic mothers. Acta Endocrinol. 15:33-52.

2. Cowett, R. M., and R. Schwartz. 1982. The infant of the diabetic mother. Pediatr. Clin. N. Am. 29:1213-1231.

3. Cornblath, M., and R. Schwartz. 1976. Infant of the diabetic mother. In Disorders of Carbohydrate Metabolism in Infancy. W. B. Saunders, Co., Philadelphia. 115-154.

4. Philipps, A. F., J. W. Dubin, P. J. Matty, and J. Raye. 1982. Arterial hypoxemia and hyperinsulinemia in the chronically hyperglycemic fetal lamb. Pediatr. Res. 16:653-658.

5. Rudolph, A. M., and M. A. Heymann. 1980. Methods for studying the circulation of the fetus in vitro. In Animal Models in Fetal Medicine. Elsevier/North Holland Biomedical Press, Amsterdam. 1-58.

6. Philipps, A. F., B. A. Carson, G. Meschia, and F. C. Battaglia. 1978. Insulin secretion in fetal and newborn sheep. Am. J. Physiol. 235:E467-E474.

7. Meschia, G., J. R. Cotter, E. L. Makowski, and D. H. Barron. 1967. Simultaneous measurement of uterine and umbilical blood flow and oxygen uptake. Q. J. Exp. Physiol. Cogn. Med. Sci. 52:1-8.

8. Koong, L. J., W. N. Garrett, and P. V. Rattray. 1975. A description of the dynamics of fetal growth in sheep. J. Anim. Sci. 41:1065-1068.

9. James, E. J., J. R. Raye, E. L. Gresham, E. L. Makowski, G. Meschia, and F. C. Battaglia. 1972. Fetal oxygen consumption, carbon dioxide production, and glucose uptake in a chronic sheep preparation. Pediatrics. 50:361-371.

10. Boyd, R. D. H., F. H. Morriss, Jr., G. Meschia, E. L. Makowski, and F. C. Battaglia. 1973. Growth of glucose and oxygen uptakes by fetuses of fed and starved ewes. Am. J. Physiol. 225:897-902.

11. Keitt, A. S. 1971. Reduced nicotinamide adenine dinucleotidelinked analysis of 2,3-diphosphoglyceric acid: spectrophotometric and fluorometric procedures. J. Lab. Clin. Med. 77:470-475.

12. Ditzel, J., and E. Standl. 1975. The problem of tissue oxygenation in diabetes mellitus. II. Evidence of disordered oxygen release from the erythrocytes of diabetics in various conditions of metabolic control. Acta Med. Scand. Suppl. 578:59-68.

13. Philipps, A. F., P. Porte, S. Stabinsky, and J. R. Raye. 1982.
Effects of chronic fetal hyperglycemia upon umbilical glucose and lactate uptake in the fetal lamb. Pediatr. Res. 17:294A.

14. Blechner, J. N. 1970. Fetal acid-base homeostasis. Clin. Obstet. Gynecol. 13:621-637.

15. Hill, E. P., G. G. Power, and L. D. Longo. 1973. A mathematical model of carbon dioxide transfer in the placenta and its interaction with oxygen. Am. J. Physiol. 224:283-299.

16. Lorijn, R. H., and L. D. Longo. 1980. Norepinephrine elevation in the fetal lamb: oxygen consumption and cardiac output. Am. J. Physiol. 239:R115-R122.

17. Lorijn, R. H., J. C. Nelson, and L. D. Longo. 1980. Induced fetal hyperthyroidism: cardiac output and oxygen consumption. Am. J. Physiol. 239:H302-H307.

18. Carson, B. S., A. F. Philipps, M. A. Simmons, F. C. Battaglia, and G. Meschia. 1980. Effects of a sustained insulin infusion upon glucose uptake and oxygenation of the ovine fetus. Pediatr. Res. 14:147152.

19. Milley, J. R., A. A. Rosenberg, A. F. Philipps, R. A. Molteni, M. D. Jones, Jr., and M. A. Simmons. 1980. Mechanisms of hypoxemia in ovine fetal hyperinsulinemia. Pediatr. Res. 14:458.

20. Rudolph, A. M., and M. A. Heymann. 1976. Cardiac output in the fetal lamb: the effects of spontaneous and induced changes of heart rate on right and left ventricular output. Am. J. Obstet. Gynecol. 124:183192.

21. Itskovitz, J., E. F. LaGamma, and A. M. Rudolph. 1983. The effect of reducing umbilical blood flow on fetal oxygenation. Am. J. Obstet. Gynecol. 145:813-818.

22. Itsokovitz, J., B. W. Goetzman, and A. M. Rudolph. 1982. Effects of hemorrhage on umbilical venous return and oxygen delivery in fetal lambs. Am. J. Physiol. 242:H543-H548.

23. Peeters, L. L. H., R. E. Sheldon, M. D. Jones, Jr., E. L. Makowski, and G. Meschia. 1979. Blood flow to fetal organs as a function of arterial oxygen content. Am. J. Obstet. Gynecol. 135:637-646.

24. Wilkening, R. B., and G. Meschia. 1983. Fetal oxygen uptake, oxygenation and acid-base balance as a function of uterine blood flow. Am. J. Physiol. 244:H749-H755.

25. Boyle, P. C., L. H. Storlien, A. E. Harper, and R. E. Keesey. 1981. Oxygen consumption and locomotor activity during restricted feeding and realimentation. Am. J. Physiol. 241:R392-R397.

26. Saltzman, H. A., and J. A. Salzano. 1971. Effects of carbohydrate metabolism upon respiratory gas exchange in normal men. J. Appl. Physiol. 30:228-231.

27. Mondejar, E. F., M. D. Lombardo, A. J. P. de la Cruz, A. M. Morales, J. M. T. Ruiz, and J. A. F. Orihuela. 1982. Variations in oxygen consumption and carbon dioxide production during parenteral nutrition. Intensive Care Med. 8:169-172.

28. Askanazi, J., Y. A. Carpentier, D. H. Elwyn, J. Nordenstrom, M. Jeevanadam, S. H. Rosenbaum, F. E. Gump, and J. M. Kinney. 1980. Influence of total parenteral nutrition on fuel utilization in injury and sepsis. Ann. Surg. 191:40-46.

29. Askanazi, J., S. H. Rosenbaum, A. Hyman, P. A. Silverberg, J. Milic-Emile, and J. M. Kinney. 1980. Respiratory changes induced by the large glucose loads of total parenteral nutrition. J. Am. Med. Assoc. 243:1444-1447.

30. Askanazi, J., D. H. Elwyn, P. A. Silverberg, S. H. Rosenbaum, and J. M. Kinney. 1980. Respiratory distress secondary to the high carbohydrate load of TPN: a case report. Surgery. 87:596-598.

31. Battaglia, F. D., and G. Meschia. 1978. Principle substrates of fetal metabolism. Physiol. Rev. 58:499-527. 
32. Rurak, D. W., and N. C. Gruber. 1983. The effect of neuromuscular blockade on oxygen consumption and blood gases in the fetal lamb. Am. J. Obstet. Gynecol. 145:258-262.

33. Natale, R., J. Patrick, and B. Richardson. 1978. Effects of human maternal venous plasma glucose concentrations on fetal breathing movements. Am. J. Obstet. Gynecol. 132:36-41.

34. Gelman, S. R., W. N. Spellacy, S. Wood, S. A. Birk, and W. Buhi. 1980. Fetal movements and ultrasound: effect of maternal intravenous glucose administration. Am. J. Obstet. Gynecol. 137:459-461.

35. Abrams, R., D. Caton, J. Clapp, and D. H. Barron. 1969. Thermal and metabolic features of life in vitro. Clin. Obstet. Gynecol. 13:549564.

36. Katz, J., and R. Rognstad. 1976. Futile cycles in the metabolism of glucose. Curr. Top. Cell. Regul. 10:237-289.

37. MacKay, R. B. 1957. Observations on the oxygenation of the foetus in normal and abnormal pregnancy. J. Obstet. Gynaecol. Br. Commonw. 64:185-197.

38. Naeye, R. L. 1965. Infants of diabetic mothers: a quantitative morphologic study. Pediatrics. 35:980-988.

39. Widness, J. A., J. B. Susa, J. F. Garcia, D. B. Singer, P. Sehgal, W. Oh, R. Schwartz, and H. C. Schwartz. 1981. Increased erythropoiesis and elevated erythropoietin in infants born to diabetic mothers and in hyperinsulinemic rhesus fetuses. J. Clin. Invest. 67:637-642.

40. Widness, J. A., J. F. Garcia, G. K. Clemons, R. L. Cavalieri, J. B. Susa, K. A. Teramo, and R. Schwartz. 1983. Temporal response of immunoreactive erythropoietin to acute hypoxemia in the sheep fetus. Pediatr. Res. 17:144A.

41. Philipps, A. F., J. A. Widness, J. F. Garcia, J. R. Raye, and R. Schwartz. 1982. Erythropoietin elevation in the chronically hyperglycemic fetal lamb. Proc. Soc. Exp. Biol. Med. 170:42-47. 